\title{
Squamous cell carcinoma of tongue 18 years after renal transplantation: a case report
}

\author{
Jyoti Poddar, Ashutosh Das Sharma, Ubrangala Suryanarayana Kunikullaya \\ Department of Radiotherapy, the Gujarat Cancer and Research Institute, Asarwa, Ahmedabad 380016, India.
}

Correspondence to: Dr. Jyoti Poddar, Department of Radiotherapy, the Gujarat Cancer and Research Institute, Asarwa, Ahmedabad 380016, India. E-mail: poddarjyo@gmail.com

How to cite this article: Poddar J, Sharma AD, Kunikullaya US. Squamous cell carcinoma of tongue 18 years after renal transplantation: a case report. J Cancer Metastasis Treat 2016;2:443-5.

\author{
Article history: \\ Received: 19-06-2016 \\ Accepted: 10-11-2016 \\ Published: 25-11-2016 \\ Key words: \\ Renal transplant, \\ immunosuppression, \\ carcinoma tongue
}

\begin{abstract}
Solid organ transplant recipients are at increased risk of developing malignancies, even decades after transplant, due to the prolonged use of immunosuppressant drugs. A 35-year-old male underwent renal transplant for end stage renal disease 18 years previously and was on immunosuppressive drugs since that time and was on regular follow up. In 2016, he developed a squamous cell carcinoma of tongue, which was operated and adjuvant radiation therapy was given. The patient is currently on follow up and asymptomatic. Though squamous cell carcinoma of tongue is a relatively common malignancy in the general population, it is very rare in transplant recipients. Hence, such patients require longer follow-up, active surveillance, and screening for early diagnosis and prompt treatment of premalignant and malignant conditions.
\end{abstract}

\section{INTRODUCTION}

Renal transplant, which is usually the treatment of choice for end stage renal failure, predisposes the recipient to an increased risk of developing malignancies and this risk increases with increasing duration of immunosuppression. ${ }^{[1]}$ This risk is largely attributable to the immunosuppressive drugs used to combat graft rejection (with an incidence of up to approximately $5 \%$ to $6 \%$ ). The malignancies commonly encountered are skin cancers and those of the lymphatic system. ${ }^{[2]}$ Of these, squamous cell carcinomas make up the bulk of epithelial carcinomas, involving most commonly skin, lips, cervix, and, rarely, lung. However, malignancies involving the tongue are an uncommon occurrence in this context, whereas it is a common intra-oral malignancy in the general population. ${ }^{[3]}$ We report such an unusual case occurring eighteen years after renal transplantation.

The purpose is to draw attention towards the need of extended follow up and active surveillance to look for malignancies in unusual locations and for early diagnosis and better management.

\section{CASE REPORT}

A 5-year-old child (1985) developed off and on reeling 
of head, generalized itching, low urine output, and generalized edema for one month. Upon investigation, he was found to have chronic kidney disease involving mainly the left kidney. It was advised that the patient undergo renal transplant but this was refused by the parents due to financial constraints. The child was kept on supportive care and follow up. At the age of 18 , he finally underwent transplant due to worsening of renal function (1998). He was then put ona azathioprine, prednisolone and cyclosporine regimen for immunosuppression following transplantation. Cyclosporine was discontinued after two years and the patient was continued on azathioprine and prednisolone. He was on regular follow-up since after, with no major complaints. In 2010, he developed hepatitis B and C co-infection and was placed on Tenofovir. In 2016, 18 years after transplantation and being on immunosuppressive therapy, he developed an ulcer on the tongue. On biopsy, it was found to be a squamous cell carcinoma. Computed tomography scan (22/04/2016) showed ill defined, hyperdense lesion, $16 \mathrm{~mm} \times 6 \mathrm{~mm}$ in size, involving the anterior aspect of left lateral border of the tongue, not crossing midline or involving the base of tongue or vallecula. There were few subcentimeter lymph nodes on the left, level Ib and II. On history, the patient had no history of chewing tobacco, smoking, or use of alcohol. Also, there was no history suggestive offactors, which could have led to chronic irritationand subsequently to malignancy. On 22/03/2016, he underwent surgical treatment (left partial glossectomy and left modified neck dissection). Histopathology report was squamous cell carcinoma [Figure 1], size $1 \mathrm{~cm} \times 0.6 \mathrm{~cm} \times 0.2 \mathrm{~cm}$. Two of 29 lymphnodes were positive, with perinodal extension. Invasion of deep muscles, lymphovascular invasion, and perineural infiltration were seen and resection margins were free of tumor. On polymerase chain reaction for human papilloma virus (HPV)-DNA, the patient was found to be HPV 16-positive. He then received postoperative radiotherapy of 60 Gray in 30 fractions, on a 6-MV linear accelerator using parallel opposed portals, with concurrent chemotherapy. The patient is currently free of disease and on follow-up.

\section{DISCUSSION}

Solid-organ transplant recipients are three to five times more vulnerable to develop malignancy. ${ }^{[4]}$ Immunosuppressive drugs predispose to malignancy by impairing immune reactions against viral infections, the most common being HPV. ${ }^{[5]}$

These viruses inhibit the $p 53$ gene and its tumor suppressive action, and initiate a cascade of reactions, inducing malignant changes. Also, hepatitis remains a
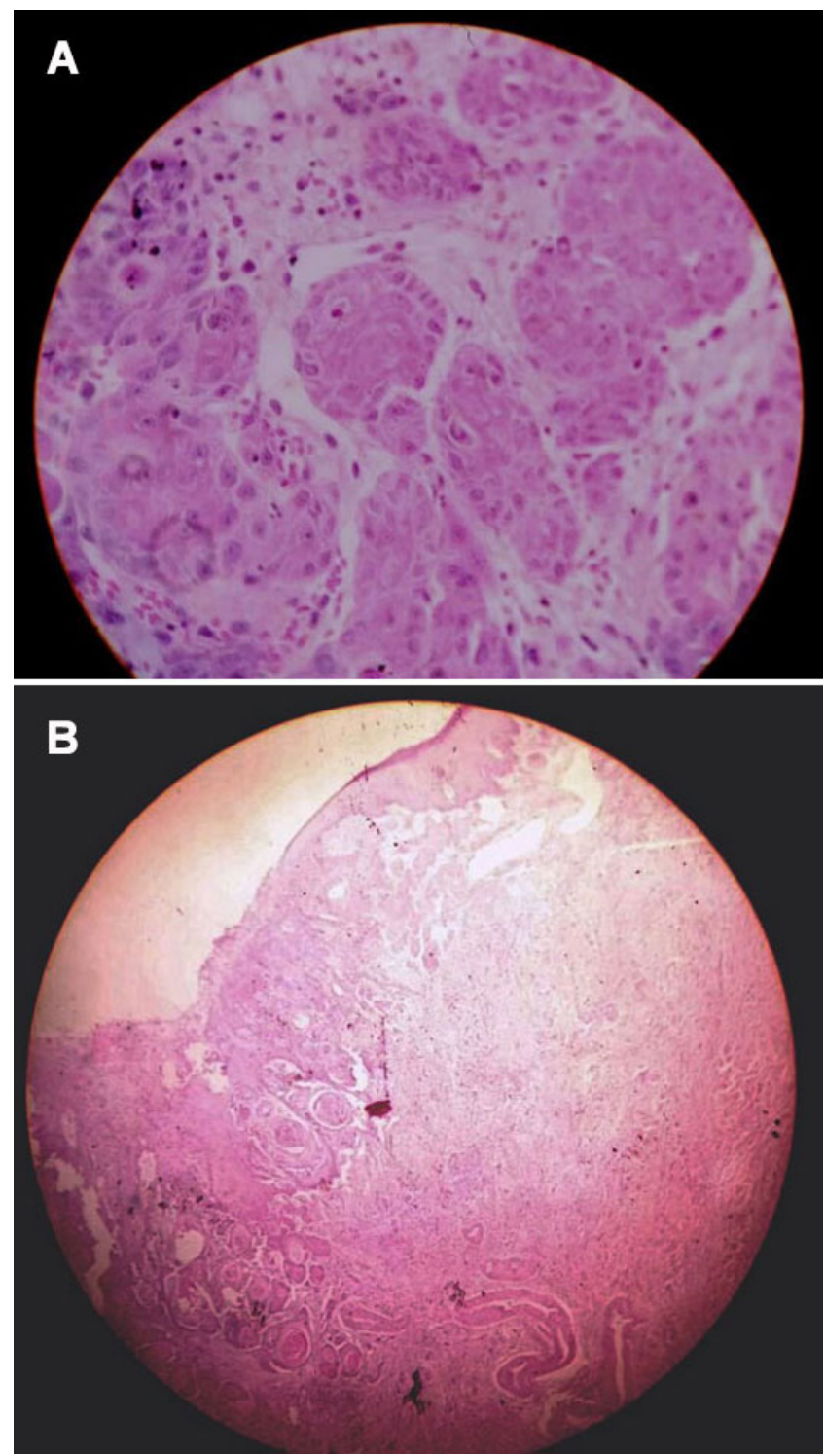

Figure 1: Power histopathology slide showing squamous cell carcinoma (A: HE, ×100; B: HE, ×40)

relevant clinical problem in patients of renal transplant. ${ }^{[6]}$ Although its incidence has decreased, nonetheless, it remains a significant problem in endemic areas and developing countries. The antiviral therapy used for hepatitis has not reported to be carcinogenic. Solid organ transplant recipients commonly suffer from fungal infections, which can even be fatal. Overall, Candidiasis tops the list and accounts for $50-60 \%$ of all fungal infections in transplant recipients. Aspergillosis is typically common in lung transplant patients. ${ }^{[7]}$ The incidence of fungal infection is around $8.6 \%$ in lung, $4.7 \%$ in liver, $3.4 \%$ in pancreas, and $1.3 \%$ in renal transplant patients. Moreover, the median time of onset of this infection ranges from several weeks to months in lung and liver transplant recipients to over two years in kidney transplants. ${ }^{[8]}$ 
The incidence of malignancy increases gradually for ten years after the transplant and becomes as high as 13.8 fold higher in such patients as compared to the normal population. The cumulative frequency increases with increase in duration of follow-up. This patient developed his cancer 18 years after transplant. ${ }^{[0]}$ Other risk factors attributable to development of malignancy in these patients is advancing age, viral infections, cigarette smoking, and transmission of malignancy from donor cells. ${ }^{[10]}$ Thus, strict follow-up and vigilance for signs and symptoms of malignancy should be followed in patients with organ transplantation on immunosuppressive drugs, even after decades of transplant.

\section{Financial support and sponsorship} Nil.

\section{Conflicts of interest}

There are no conflicts of interest.

\section{Patient consent}

Patient consent was obtained from the patient.

\section{Ethics approval}

Ethics approval was obtained from the institutional ethical committee for preparation and publication of this paper.

\section{REFERENCES}

1. Chapman JR, Webster AC. Cancer after renal transplantation: the next challenge. Am J Transplant 2004;4:841-2.

2. Malleshappa P, Aghariya M, Tampi C, Shah BV. Squamous cell carcinoma of tongue in a renal transplant recipient. Indian $\mathrm{J} \mathrm{Med}$ Paediatr Oncol 2009;30:136-7.

3. Lee YW, Gisser SD. Squamous cell carcinoma of the tongue in a nine year renal transplant survivor: a case report with a discussion of the risk of development of epithelial carcinomas in renal transplant survivors. Cancer 1978;41:1-6.

4. Rama I, Grinyó JM. Malignancy after renal transplantation: the role of immunosuppression. Nat Rev Nephrol 2010;6:511-9.

5. Sheil AG. Cancer report 2001. In: Ross GR, editor. ANZDATA Registry Report 2001. Adelaide, South Australia: Australia and New Zealand Dialysis and Transplant Registry; 2001. p. 84-90.

6. Tsai MC, Chen YT, Chien YS, Chen TC, Hu TH. Hepatitis B virus infection and renal transplantation. World $J$ Gastroenterol 2010;16:3878-87.

7. Silveira FP, Husain S. Fungal infections in solid organ transplantation. Med Mycol 2007;45:305-20.

8. Shoham S, Marr KA. Invasive fungal infections in solid organ transplant recipients. Future Microbiol 2012;7:639-55.

9. Yang TC, Shu KH, Cheng CH, Wu MJ, Lian JD. Malignancy following renal transplantation. Zhonghua Yi Xue Za Zhi (Taipei) 1998;61:281-8.

10. Danpanich E, Kasiske BL. Risk factors for cancer in renal transplan recipients. Transplantation 1999;68:1859-64 